\title{
Representações sociais e território nas letras de funk proibido de facção
}

\author{
Social representations and territory in proibido de facção funk lyrics \\ Representaciones sociales y territorio em letras de funk proibido de facção
}

\author{
Andréa Rodriguez \\ Rhaniele Sodré Ferreira* \\ Angela Arruda ${ }^{* * *}$
}

\begin{abstract}
Resumo
Este artigo apresenta, por meio de uma análise de letras de funk "proibido de facção", uma leitura da territorialidade do tráfico de drogas nas favelas. Esse estilo musical, que expressa uma cultura específica da juventude urbana pobre, revela cenas de um cotidiano pouco conhecido pela maior parte da população. Para tal, foi realizada a análise do conteúdo de 50 letras de funk, de forma a se compreenderem questóes que esse tipo de narrativa faz circular. Destaca-se o território e a territorialidade como categorias de análise que revelam a dinâmica que o tráfico de drogas impóe nos espaços populares da cidade e que incidem diretamente nas representações sociais e práticas dos moradores das favelas.
\end{abstract}

Palavras-chave: Território, representações sociais, funk, tráfico de drogas.

\begin{abstract}
This article aims to analyse how territoriality of drug trafficking in favelas is expressed in funk lyrics. Those songs represent a unique urban culture produced for poor youth living in favelas. It reveals a daily reality that goes overlooked by most people which produces negative effects among favela residents. For that, it was developed an analysis of fifty lyrics of "forbidden funk" style songs. In those funk songs, we highlight territory as an important category of analysis which shows the social dynamic that gangs develop in favelas. Here we understand that through funk lyrics it is possible to "read" some aspects of the consequences of
\end{abstract}

\footnotetext{
Texto recebido em julho de 2010 e aprovado para publicação em março de 2011.

Doutora em Psicologia pela Universidade Federal do Rio de Janeiro, consultora em projetos e pesquisa social. E-mail: andreasrodriguez12@yahoo.com.br.

-* Mestranda no International Human Resource Management - Universidade de Greenwich (Londres, Inglaterra), psicóloga graduada pela Universidade Federal do Rio de Janeiro. E-mail: rhaniele@gmail.com.

${ }^{* * *}$ Doutora em Psicologia (Universidade de São Paulo), professora do Instituto de Psicologia da UFRJ. E-mail: arrudaa@ centroin.com.br.
} 
the territorialisation of drug trafficking in the life, social representation and social practices of favelas residents.

Keywords: Territory, social representations, funk, drug trafficking.

\section{Resumen}

Este artículo introduce la manera como la territorialidad de barrios marginales, dibujado por grupos vinculados al tráfico de drogas, es expresada en letras de "funk de fracción", el cual es prohibido. Para esto, se llevó a cabo el análisis de contenido de 50 letras de esa vertiente Del funk, con el fin de entender las cuestiones que este tipo de narrativa circula. Esas canciones, manifestación de una específica cultura de la juventud urbana pobre, diseña escenas de la vida cotidiana desconocidos para buena parte de la población Carioca, con efectos directos sobre los que viven en esos lugares. Destacándose el territorio y la territorialidad como categoría analítica reveladora de la dinámica social que estos grupos imprimen a los espacios populares de la ciudad. Las letras de funk de fracción ofrecen una lectura sobre el desdoblamiento de la territoriedad del tráfico en la vida, las representaciones y las prácticas de los habitantes de los barrios marginales.

Palabras-chave: Territorio, representaciones sociales, funk, tráfico de drogas.

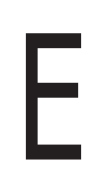

ste artigo tem como objetivo abordar a forma como a territorialidade das favelas, desenhada por grupos ligados ao tráfico de drogas, se expressa em letras de funk proibido de facção. Essa vertente do funk, produzido em favelas da cidade do Rio de Janeiro, não pode ser tocada na mídia oficial devido à descrição/exaltação da vida bandida, geralmente em ligação com as principais facções criminosas que controlam o tráfico de drogas na cidade. Para tal, foi realizada a análise de conteúdo de 50 letras dessa vertente do funk, de forma a compreender questôes que o tipo de narrativa faz circular. Tais músicas, manifestação de uma cultura específica da juventude urbana pobre, desenham cenas de um cotidiano desconhecido para boa parcela da população carioca, com efeitos diretos sobre quem reside nesses locais. No entanto, revelam também uma forma singular de transformar a violência em diversão, cantando e dançando feitos do dia a dia.

Destaca-se em particular a emergência do território como categoria de análise reveladora da dinâmica social que esses grupos imprimem nos espaços 
populares da cidade. As letras de funk de facção oferecem uma leitura sobre os desdobramentos da territorialização do tráfico na vida, representações e práticas dos moradores das favelas.

O percurso teve seu início com a pesquisa "O universo do funk proibido no Rio de Janeiro", ${ }^{1}$ pela qual tivemos uma primeira aproximação do conjunto de letras de funk proibido de facção. A explicitação de fronteiras físicas e simbólicas que os grupos do tráfico estabelecem entre si foi um elemento bastante presente nas letras.

A enunciação de territórios nas músicas de funk não é uma novidade. Herschmann (2005), ao descrever o funk da década de 1990, já dizia: "Esses cantores/compositores prestam também homenagem a seus locais de origem, transformando-os em tema central (ou secundário) do rap" (p. 166). Tal recurso, segundo o autor, teria relação com o desejo de ser reconhecido por meio da menção aos seus territórios de origem, de reinscrever os seus mundos no conjunto da cidade.

Nos funks proibidos de facção ou "proibidōes" de facção (termo mais comum entre os apreciadores e consumidores desse estilo musical), os territórios dominados pelo tráfico de drogas são evocados frequentemente, e essa enunciação está sempre relacionada à facção criminosa. Territórios aliados são homenageados, territórios de origem são exaltados, e os cobiçados são listados como os próximos alvos de invasão. A facção, ao se apropriar de um território e fazer uso dele, normatiza regras de convívio para aqueles que aí residem, deixando a sua marca e fazendo com que aqueles não ligados às atividades do tráfico, como crianças, adolescentes e jovens das comunidades, vejam-se na contingência de adotar os códigos da facção.

Em trabalho realizado com adolescentes na favela Nova Holanda, comunidade que integra o Complexo da Maré, maior conjunto de favelas do Estado do Rio de Janeiro, apreendemos uma série de falas que corroboram o que foi dito acima. Numa oficina psicossocial, ${ }^{2}$ um adolescente falou sobre o proibidão: "As músicas do CV (facção Comando Vermelho) são as melhores, os outros nos copiam". Outro adolescente continuou: "Os melhores MCs são do CV". Um terceiro acrescentou: "As músicas do TCP (facção Terceiro Comando Puro) são horríveis, não têm nada”. Levando-se

\footnotetext{
Vinculado ao Núcleo de Pesquisas Cognição \& Coletivos e à linha de pesquisa "Processos psicossociais e coletivos", do Programa de Pós-graduação em Psicologia da UFRJ, com financiamento da FAPERJ.

As oficinas fizeram parte do projeto de extensão da UFRJ, intitulado "Construindo novos olhares com jovens de baixa renda”. Elas ocorreram na ONG Instituto Vida Real, situada na favela da Maré, Rio de Janeiro, entre março e junho de 2009, com adolescentes de 13 a 17 anos.

Mestre de cerimônia ou MC é o anfitriāo de um evento público ou privado de música; em geral, nos estilos hip-hop e funk.
} 
em conta que a facção que controla o tráfico de drogas nessa favela era o Comando Vermelho, observa-se a interiorização de uma disputa que, na verdade, pertence às diferentes facções e não aos moradores locais. Alguns garotos que participaram da oficina manifestaram preferência pela facção que domina a sua área, vista como "melhor" que a outra, ainda que num âmbito musical.

A questão da territorialidade, expressa nas letras de funk de facção, será apresentada ao longo do texto. De início, faremos um breve histórico do funk no Rio de Janeiro para compreendermos as condiçôes que possibilitaram o surgimento do funk proibido de facção. Em seguida, explicitaremos a metodologia de análise das letras e discutiremos um conjunto de elementos que conjugam as noções de território e territorialização (presente nas letras), jogos de força que compóem campos de poder diferenciados, incidindo na produção de novas relações e práticas com os territórios.

\section{Funk no Brasil: um breve histórico}

O funk ganhou visibilidade no Brasil no começo da década de 1970, com os "bailes da pesada", que reuniam um público de 5000 pessoas por domingo no Canecão, casa de shows na Zona Sul do Rio de Janeiro. Na primeira metade dessa década, os bailes foram transferidos para clubes do subúrbio, e o funk então viveu a fase de valorização da cultura negra, apelidada pela imprensa da época de Black Rio (Vianna, 1988).

A nacionalização do funk tornou-se completa na década de 1990, iniciada pelo DJ Marlboro com o disco "Funk Brasil 1", em 1989. A inserção de instrumentos originários do samba, como o atabaque e o tamborim, contribuiu para o surgimento de um "funk carioca", já bem diferente daquele que um dia foi importado dos EUA (Guedes, 2007). As letras das músicas começaram a ser cantadas em português e a trazer como tema questôes do cotidiano das favelas e bairros pobres. ${ }^{4}$ É nessa mesma conjuntura, entretanto, que o funk e o funkeiro começaram a ser mais associados à violência, principalmente quando recaía sobre ele a culpa pelo arrastão ocorrido na praia do Arpoador, na capital fluminense, em 1992 (Arruda et al., 2010). Na mesma época, a ação conjunta de jovens e crianças que praticavam furtos a turistas no calçadão de Copacabana já tinha sido chamada de "arrastão" (Herschmann, 2005; Medeiros, 2006).

\footnotetext{
4 O "Rap da Felicidade", por exemplo, tornou-se um sucesso nacional com o refrão "Eu só quero é ser feliz, andar tranquilamente na favela onde eu nasci / E poder me orgulhar e ter a consciência que o pobre tem seu lugar" (Kátia/Julinho Rasta, 1994).
} 
O debate sobre a associação entre funk e violência atravessa a década e, em 1995, foi criada a primeira Comissão Parlamentar de Inquérito (CPI) para investigar a relação entre funk e tráfico de drogas, o que gerou a proibição de diversos bailes. O funk passou a ser vinculado à Secretaria de Segurança Pública desde então. Somente em 2009, a Lei Álvaro Lins (5.625/2008), que restringia a realização de bailes funks no Estado, foi revogada, passando a vigorar a Lei 5.543/2009, que reconhece o funk como movimento cultural. Esse movimento de repressão ao funk reuniu um conjunto de fatores que contribuiu para o surgimento do proibidão de facção, uma vez que os bailes saíram dos clubes e passaram a ser realizados, em sua maioria, dentro das comunidades, com o apoio e o financiamento dos traficantes de drogas.

Guedes (2007, p. 78) define o proibidão como o funk "que faz apologia ao narcotráfico, com exaltação das façanhas criminosas e violentas, e expressa o ódio e a morte dos seus inimigos: a polícia e as facções rivais". O primeiro proibidão a ganhar visibilidade na mídia foi o "Rap do Comando Vermelho", em 1999. Chocou o conteúdo extremamente violento da letra, ao descrever a punição de um X9 ou traidor: "Cheiro de pneu queimado / carburador furado / e o X9 foi torrado / quero contenção do lado / tem tiro no miolo / e o meu fuzil está destravado".

É a partir daí que se teve conhecimento de funks ligados às principais facções do Rio de Janeiro: o Comando Vermelho (CV), o Terceiro Comando (TC) e os Amigos dos Amigos (ADA).

\section{Territorialidade, tráfico e representações sociais}

A concepção de território a partir da relação sociedade-espaço que ela expressa compreende formas de abordá-lo nas perspectivas funcional e simbólica. No caráter simbólico, o território é visto como espaço de sedimentação simbólico-cultural, objeto de investimento afetivo ou suporte de identidades individuais e coletivas (Giménez, 2000). A dimensão simbólica do termo expressa as identidades territoriais e a identificação que determinados grupos sociais desenvolvem com seus espaços vividos (Haesbaert, 2002). O território se caracteriza por seu valor de uso, resultado de uma ação conduzida por um ator/atores, em diferenciados níveis (Raffestin, 1993).

Nas sociedades contemporâneas, há varias estratégias para a afirmação de um poder ou para reforçar uma dominação já existente. A territorialização de áreas pelo tráfico envolve processos de apropriação e controle inscritos 
num campo de poder (físico e simbólico), além de laços de identidade com a facção que tenta, de alguma forma, homogeneizar e demarcar o território com uma fronteira definidora de alteridade.

O tráfico de drogas hoje é uma atividade ilícita realizada por grupos armados e territorializados que, por uma organização e disputa interna do espaço, garantem a reprodução de suas atividades. A territorialidade que o tráfico impõe na cidade nada mais é que a expressão espacial e de poder das práticas desses grupos, o que nos remete a uma relação específica de uso, apropriação e domínio de espaços (físicos e simbólicos). As formas e os mecanismos utilizados nos seus processos de territorialização abrangem determinadas referências simbólicas, delimitam fronteiras e legitimam o uso da força e coação para aqueles que desrespeitam as restrições impostas (Silva et al., 2008).

Tais organizações se apresentam nos territórios de sua ação impondo aos moradores uma circulação restrita. Na prática, o poder da facção e o medo que ela provoca, associados às disputas com outras facções, interditam aos membros de seu grupo e também aos outros moradores o acesso a partes da cidade, de forma total ou parcial. Desse modo, adolescentes e jovens do sexo masculino, em especial, estão mais visados quanto à circulação por territórios sob o domínio de uma facção rival, embora os demais moradores das favelas sob domínio do tráfico também enfrentem tais restrições (Leite \& Oliveira, 2005; Fernandes, 2009).

Na perspectiva de Jodelet (1984), as representações sociais como fenômenos se apresentam sob formas variadas e condensam um conjunto de significações e sistemas de referências que nos permitem interpretar o que nos acontece por meio de categorias que servem tanto para classificar as circunstâncias e os acontecimentos da vida como os indivíduos e grupos com os quais temos contato. Com a presença do tráfico e suas demarcaçōes territoriais, mudanças significativas no sentido e nas representações sociais de populações residentes em favelas acerca do espaço em que vivem geram novas relaçōes de interação com os territórios.

Contudo, na perspectiva do criador da teoria, Moscovici (1978), o sujeito das representações sociais é ativo no movimento de atribuição de sentido aos objetos do cotidiano, pois opera sobre eles e lança mão da criatividade; nesse caso, para interagir e viver as múltiplas territorialidades presentes no contemporâneo.

O controle do acesso ao território demarcado pela facção é feito, sobretudo, pela fronteira (local que separa uma facção da outra). As fronteiras em cada 
território, mesmo que não tenham marcações visíveis, têm uma existência real com a qual é preciso contar (Raffestin, 1993). As fronteiras do tráfico são traçadas conforme a distribuição das bocas de fumo (pontos de venda de drogas) no interior das favelas. Podem ser ruas, valas, esquinas, muros que marcam onde começa e onde termina o poder de uma facção. Geralmente são alvos constantes de conflito e troca de tiros, principalmente quando há tentativas de invasão de outra facção, já que seus integrantes concentram-se em local próximo às fronteiras para garantir a sua defesa e fortalecimento.

A territorialização é também uma estratégia de autoproteção que se exerce com a contenção, restrição e exclusão de pessoas em determinados espaços. Assim, os traficantes tentam se prevenir quanto à passagem de informações sobre os pontos de venda e a estrutura interna a facções rivais. Desse modo, os recortes espaciais flexíveis e dinâmicos (porque mudam de acordo com as invasões e tomadas de poder de uma facção sobre a outra) acabam produzindo determinados sentidos sobre as fronteiras do tráfico (amplamente compartilhadas pelos moradores locais). Essas fronteiras, que redesenham o mapa geográfico e mental desses espaços, são simbolizadas, nas falas de adolescentes moradores, como áreas "perigosas", "onde não dá para ficar", "onde os tiroteios são mais frequentes", onde "eu evito passar". Esse aspecto ficou bem marcado em oficinas do projeto de extensão (já citado) com adolescentes no Complexo da Maré, em que pedimos que os participantes desenhassem sua comunidade. Dois adolescentes comentaram: "Desenha a Baixa [do Sapateiro], que eu desenho a Nova Holanda, ai a gente troca tiro pelo desenho!" (duas regiões da Maré controladas por facções rivais na época). Outro desenho foi marcado por símbolos da facção Comando Vermelho, com homens armados dispostos em diferentes pontos da favela, apontando para uma distribuição estratégica do grupo em relação ao controle do território. Em mais outro desenho, havia clara demarcação da área de outra facção, com as casas desenhadas enfileiradas lado a lado e, no sentido oposto, uma inscrição do nome da outra localidade.

Atualmente a cidade do Rio de Janeiro conta com uma nova política de segurança pública em favelas. Desde dezembro de 2008, o governo do Estado iniciou o projeto das unidades de polícia pacificadora (UPPs), que têm como princípio a ocupação de territórios dominados pelo tráfico e a implantação paralela de um conjunto de ações sociais. As UPPs vêm buscando integrar os moradores às ações, de modo a se restabelecerem relações de confiança entre a comunidade e a polícia. Os resultados e impactos das intervenções das UPPs ainda não foram sistematicamente avaliados. Todavia é possível dizer que os moradores ainda se dividem entre 
a desconfiança e o medo (dada a relação histórica da polícia com eles), e a incerteza quanto à perduração dessa política, a exemplo de tantas outras que falharam. Com isso, embora o discurso oficial venha buscando demonstrar que existe uma maior integração entre moradores e polícia, não é garantia de que esses estejam realmente confiantes em que a política se mantenha. E ainda há o problema dos grupos de traficantes que se encontram apenas "temporariamente" afastados das atividades em nível local ou, em alguns casos, apenas atuando de uma forma mais discreta e menos ostensiva nas favelas onde as UPPs se instalaram. Apesar disso, é possível dizer que essa política vem redesenhando, ainda que temporariamente, a dinâmica do território, permitindo uma retomada gradativa de espaços antes ocupados pelo tráfico e impondo uma nova ordem socioespacial, como a proibição de bailes funk e uma espécie de "toque de recolher".

\section{Vivendo as fronteiras: identidade com o tráfico ou apenas “jogando o jogo"?}

Para quem não reside em espaços dominados por facções criminosas, é difícil mensurar o quanto a liberdade de circulação pode ser cerceada. A problemática que envolve as fronteiras do tráfico é nítida se a abordamos com base na ótica de seus principais envolvidos: jovens moradores dos espaços territorializados, em especial do sexo masculino. A percepção das fronteiras para aqueles que não a vivenciam é muito diferente daqueles que a vivem no cotidiano ou que moram nas áreas fronteiriças (Giménez, 2007). Desse modo, a fronteira realmente existente é aquela vivida na experiência dos atores sociais situados em seu entorno.

A noção de experiência, em Jodelet (2005), parte de situações concretas que os sujeitos deparam em seus cotidianos. Nesse caso, uma tentativa de aproximação de indícios de representações que esses moradores, impedidos de circular por alguns pontos da favela, passam a ter sobre o próprio lugar de moradia nos remete à própria experiência vivida nos territórios e os sentidos atribuídos pelos sujeitos que a vivem. Quais transformaçôes em suas representações seriam provocadas por essa experiência de restrita circulação?

Sujeitos se integram em diferentes grupos sociais e assumem identidades coletivas (Andrade, 1998) ao longo de suas existências. Para alguns adolescentes e jovens nas favelas, o que parece ocorrer é o desenvolvimento de sentimentos de pertencimento aos valores e práticas de grupos ligados ao tráfico, sem que isso queira dizer que assumem a identidade territorial 
da facção que domina a sua área. Pela nossa experiência de intervenção psicossocial ${ }^{5}$ em comunidades que sofrem ingerência do tráfico, o que se viu, no geral, é o cumprimento de determinadas regras de conduta, sem que isso represente uma adesão, de fato, ou a expressão de um sentimento de identidade e pertencimento à facção, por mais que assim pareça num primeiro momento. Convivência e proximidade forçadas com o tráfico exigem estratégias específicas para lidar com a situação. Isso é constantemente entendido, por grande parte da opinião pública, como conivência e aceitação da população do entorno às atividades do tráfico. $\mathrm{Na}$ verdade, a coerção que a presença do tráfico impóe e o temor que ela provoca na cidade reverberam de maneira ambivalente na comunidade: a discriminação que assimila todos os seus moradores a bandidos se mistura com a visibilidade que ganham, como uma manifestação de respeito por serem associados ao território sob o comando da facção $\mathrm{X}$ ou Y (uma espécie perversa de reconhecimento).

A identificação, no caso, tem a ver com o desejo de pertencimento a algo que expressa um poder, impõe um respeito de que essas populações não costumam gozar. Não quer dizer concordar com as atividades da facção, mas sim nutrir uma espécie de admiração relativa por algo que não se tem: uma força, uma potência, um vínculo com o poder. Esse tipo de sentimento parece vir mais dos jovens, adolescentes, num período da vida em que as questôes de identificação estão à flor da pele, na busca de um status menos ambíguo que o de simplesmente ser criança ou adolescente morador de favela, com todos os estigmas (Valladares, 2000) que esse fato carrega. A população jovem e predominantemente masculina parece ser a mais sensível ao apelo dos cantos da facção, que, na maioria das vezes, perde importância com a idade. Se tomarmos o funk proibido de facção como indicador desse sentimento de "simpatia" pela crônica da vida bandida exaltada nas letras, a idade seria um aspecto limitador. Nesse caso, a identificação de crianças e adolescentes aos símbolos da facção que domina a sua área, visto nas oficinas do projeto, seria uma identificação simbólica, da ordem do desejo de poder, de reconhecimento, só efetivado realmente por uma minoria, a que entra para o tráfico. De resto, para a população de modo geral, a proximidade com a dinâmica do tráfico nas favelas traz uma convivência diária que pode reproduzir um tipo de adesão aos seus códigos e valores, mas que,

\footnotetext{
No projeto de extensão já citado, realizamos oficinas e atendimentos psicossociais com adolescentes e jovens de duas instituições da Maré. Além disso, uma das autoras esteve vinculada a organizações em favelas por vários anos, tendo tido a possibilidade de conhecer, pesquisar e intervir nesse universo.
} 
na verdade, somente indica a necessidade de "entrar no jogo", não bater de frente com o comando, para não ter problemas futuros.

Com as UPPs, não se sabe ainda os rumos que essa ordem tomará. Os jornais noticiam que o tráfico prossegue, sem armas e escondido. O que dá certo conforto aos moradores, mas, por outro lado, traz prejuízos e outra forma de controle à vida deles (imposição de uma nova ordem?), como a proibição de bailes, de ouvir funk, de ficar na rua até certo horário, entre outros.

O tráfico, tal como ele se manifesta nas favelas, trouxe novos elementos que levaram à necessidade de ressignificar o local de moradia. A experiência de presenciar tanto as façanhas do tráfico quanto a violência que acomete o espaço de moradia concorre para uma elaboração de afetos, complexa e contraditória. Complexa porque revela uma série de aspectos que, não relacionados entre si, podem culminar em análises superficiais da questão, como a criminalização crescente da juventude pobre que reside em favelas, identificados, de forma geral, como potenciais criminosos. Os favelados passam então a ameaçar a ordem urbana pelo viés da violência exercida pelo tráfico. Contraditório porque, ao mesmo tempo em que cria transtornos à vida dos moradores que presenciam e sofrem diretamente a sua violência e restrições espaciais, os traficantes também servem de referência para muitas crianças e jovens que se utilizam de seus vocabulários, códigos e símbolos como forma de valorização e visibilidade de suas comunidades.

O domínio territorial do tráfico restringe a circulação não só de seus integrantes. Isso é expresso quando um morador adota caminhos alternativos à fronteira com a facção rival, por exemplo, o que o faz gastar mais tempo e até recursos financeiros com o deslocamento; ou quando um jovem sente medo ou evita falar com outro que mora em comunidade dominada por facção rival, ou quando não pode visitar parentes que residem fora; ou ainda, e mais doloroso, quando o acesso a bens e serviços que materializam direitos do cidadão $^{6}$ sofre restrições porque se encontram para além da fronteira (Fernandes, 2009).

Em todas as situações mencionadas acima, a vivência no território cria práticas e novas relaçôes com os espaços, que se renovam a cada dia com base na própria instabilidade nos domínios de território pelas facções. Os termos nos quais serão formulados essa experiência de vida de cada grupo ou pessoa

\footnotetext{
6 No acompanhamento social de jovens da Maré, por diversas vezes, a utilização de dispositivos públicos de garantia de direitos, como um centro de ação social, na comunidade Baixa do Sapateiro, de domínio de facção rival à comunidade da Nova Holanda, eram evitados por moradores desta última. Eles necessitavam muito do serviço, mas se sentiam inseguros de cruzar a rua que separava os territórios das duas facçōes e serem confundidos com a figura do X9.
} 
emergem de um estoque comum de saberes que dão forma e conteúdo a essa experiência. A experiência social abordada por Jodelet (2005) comporta duas dimensões: uma da ordem da implicação psicológica do sujeito, que contém o peso e a coloração afetivos do vivido, e outra, uma dimensão cognitiva, quando favorece uma experimentação do mundo e contribui para a construção da realidade socialmente dada.

\section{O processo de análise das letras de funk proibido de facção}

$\mathrm{Na}$ tentativa de compreender o universo do funk proibido de facção, de um acervo de aproximadamente 550 músicas retiradas de CDs piratas adquiridos no comércio informal da cidade, foram transcritas inicialmente 78 letras. Destas, 50 faziam referência ao Comando Vermelho. Elas foram trabalhadas pela técnica de análise de conteúdo temático proposta por Bardin (2003).

Como o proibidão de facção é muitas vezes fruto de uma produção coletiva, sendo recriado a todo o momento, não foi possível identificar a autoria das cançôes. As menções que as próprias letras fazem sobre a facção ou sobre determinados traficantes ou localidades nos permitiram identificar a letra da música como pertencente a uma facção ou outra. $\mathrm{O}$ trabalho exigiu um longo tempo de contato com o material e o auxílio de conhecedores do gênero ${ }^{7}$ para que o vocabulário ou as gírias próprias da facção pudessem ser entendidas, bem como alguns episódios marcantes na história do comando, bastante evocados nesse corpus.

Temas centrais foram identificados nas 50 letras, dando origem a uma matriz de categorização. $\mathrm{Na}$ análise, buscou-se entender como os temas se entrelaçam e que sentidos produzem, sem tentar impor uma grade prévia de leitura sobre o material. Vale ressaltar que um mesmo material pode suscitar outras matrizes, de acordo com critérios e objetivos variados, visto que o processo de construção das categorias não é neutro nem exclusivo (Bardin, 2003).

Sete categorias (algumas divididas em subcategorias) compõem essa matriz: (1) conflitos externos à facção; (2) normas de conduta; (3) afirmação da identidade da facção; (4) afirmação da identidade guerreira; (5) consumo e demonstração de poder; (6) uso de drogas; (7) as dificuldades dessa atividade. Como se observa a seguir, a maioria delas gravita em torno da questão da territorialidade, sendo os conflitos, as normas e a afirmação

Agradecemos a contribuição decisiva de Thiago Vieira, historiador, atualmente mestrando em Psicologia na UFRJ. 
da identidade da facção as que mais claramente configuram a dimensão da luta e preservação do território.

A primeira categoria, os conflitos externos à facção, apresenta duas subcategorias que objetivam as principais ameaças ao domínio do território: a polícia ("fez inimigo de bota preta [polícia] / éum bom inimigo, bandido também") e uma facção rival ("contra o Terceiro Comando é que eu vou lutar"). Além de retratar o constante clima de conflito vivido pelos envolvidos com o tráfico e pelos moradores das favelas do Rio de Janeiro, sinaliza para a necessidade da defesa contra invasôes policiais e de grupos rivais para que a força da facção e o seu domínio não sejam abalados.

A segunda categoria refere-se às normas de conduta instituídas com base na dinâmica de funcionamento das atividades do tráfico. Elas esclarecem aos membros e não membros sobre o que se deve ou não fazer no cotidiano do tráfico, na luta, bem como as punições relativas à quebra dessas regras ("pra morar em Vigário, tem que fechar com a gente"). Tratase de um código de conduta destinado a preservar o bom funcionamento dos negócios e a salvaguarda do território. A figura do X9, por exemplo, é execrada: o delator é o inimigo número um, aquele que pode colocar interesses e vidas do grupo em risco. Ele traduz em uma mesma figura a traição e a violência que recai sobre ela (cf. letra do "Rap do Comando Vermelho", já citada), o castigo exemplar em defesa dos territórios do tráfico. Ele objetiva a ideia do perigo que vem de dentro e o que é preciso fazer para eliminá-lo, que é parte da pedagogia da facção.

A terceira, afirmação da identidade da facção, registra nas letras características particulares do CV que o constituem como grupo. Expressa a ideologia, os preceitos e os propósitos da facção, englobando as referências que levam os ouvintes a identificarem o $\mathrm{CV}$ nas músicas cantadas, mesmo que seu nome não seja mencionado. Trata-se de um conjunto de elementos demarcatórios do território identitário da facção, que incluem o resgate da memória originária, da missão, o que nos remete à história do CV ("1979, foi fundada a maior faç̧ão criminosa do RJ: o Comando Vermelho, pelo Rogério Lemgruber e seus comparsas... "); a territorialidade, com a marcação do território conquistado ("Vigário é $C V$ "); as homenagens aos amigos mortos ou presos ("Liberdade pro Marcinho"); lemas ou "slogans" ("Fé em Deus", "Paz, justiça e liberdade"). Há também as referências ao arsenal bélico ("Tu tá ligado que a $\mathrm{AK}^{8}$

\footnotetext{
${ }^{8}$ Tipo de fuzil.
} 
vaza aqui também"), exaltação à força e ao poderio da facção ("Comando Vermelho no Rio ninguém supera") e grupos internos da facção ("É o bonde do Borel').

Já a quarta categoria se refere à identidade do guerreiro, nesse caso, o traficante, aquele que inclui a violência entre as formas de afirmação da virilidade (Zaluar, 1994). Essa temática se expressa por meio de dois contornos: o do bom guerreiro, aquele que não foge de sua missão ("Sou guerreira, sou certa e não admito falha”) e o do mau guerreiro, que não consegue aturar a guerra, foge ou se entrega e, por isso, é negativizado pelo tráfico na sua normatização dos comportamentos. Tal categoria se relaciona com as que compóem o código de conduta, ao desenhar o perfil ideal do combatente da facção e seu oposto.

$\mathrm{Na}$ quinta categoria, a questão é o consumo como demonstração de poder ("É Civic, é Honda, é Audi, é S10, é Pejô e BMW, pra nós é brinquedo"), cabendo à sexta categoria as referências ao consumo e venda de drogas ("Estou a dois passos do pó de 5 / não sei se vou comprar").

Por fim, as dificuldades enfrentadas na vida do crime, última categoria, expressam o risco de morte iminente ("Hoje é que é o dia, mas o amanhã pode não mais chegar"), o sofrimento dos parentes ("Olha a mãe dele rezando pra que a polícia não passe ali”) e outras dificuldades inerentes à inserção nesse tipo de atividade ("Olha a vida desse moço que nem toda noite consegue dormir").

Neste artigo, o foco é a questão da territorialidade (expressa sobretudo na categoria afirmação da identidade da facção), ${ }^{9}$ por ser bastante expressiva no corpus trabalhado: ela aparece em quase $76 \%$ das 50 letras. ${ }^{10}$

\section{A territorialidade nos proibidóes de facção}

Os territórios dominados pelo tráfico aparecem nas músicas de funk proibido de facção como elementos indissociáveis. A demarcação desses territórios e a criação de uma identificação com eles são muito importantes para a dinâmica do tráfico, já que as diversas facções estão em constante disputa por novos pontos de venda de drogas. Como vimos, a atividade do tráfico necessita de um substrato espacial para alcançar os

\footnotetext{
A questão da identidade da facção está presente em $94 \%$ das letras analisadas, o que significa que apenas 3 letras de um total de 50 não são atravessadas por elementos que compõem essa categoria.

${ }^{10}$ Para analisar a expressividade dessa subcategoria, uma planilha de ausência e presença foi construída. As outras duas subcategorias mais frequentes foram "expressōes identitárias" (46\%) e "grupos internos da facção" (46\%).
} 
seus objetivos comerciais, e os lucros e a dominação dos traficantes ocorrem nos seus territórios. Segundo Silva, Fernandes e Willadino (2008):

O peso atribuído a referências simbólicas na demarcação das fronteiras e limites, bem como o uso da força e da coação são estratégias que os grupos criminosos lançam mão nesse processo. Outros mecanismos, mais sutis, como a popularidade de um indivíduo ou grupo, também podem servir de suporte à territorialização, garantindo legitimidade sobre a área dominada frente aos seus ocupantes ou vizinhos (Silva et al., 2008, p. 17).

É no território, portanto, que as relações de poder são estabelecidas. Ele se configura como suporte e produto das açôes de atores sociais, que se apropriam do espaço e produzem processos sociais vinculados a identidades (Raffestin, 1993). Daí a importância da demarcação de territórios na construção identitária de grupos ligados à facção Comando Vermelho. Alguns trechos de proibidão apontam essa ligação estreita entre território e facção: "A gente luta por CV, Comando Vermelho legal / Nós somos da Antares-CV,14 o bonde que porta parafal15 / Aqui somos todos irmãos / Nosso sobrenome é CV" (Letra 1).16

"Se tentar invadir Vigário 17, a bala vai cantar / Párapápápá Párapápápá. Nós somos tradição, eu já disse pra você / Vigário é CV, Vigário é CV" (Letra 2).

O território é cantado de diferentes formas: homenageado por pertencer a um grupo aliado; cobiçado, anunciado como o próximo alvo de invasão; personificado, indissociável da facção à qual pertence; ou simplesmente como a casa, a morada:

Invadimos o Macaco, 18 ficamos sorrindo à toa / Brevemente o novo lance vai ser no Morro da Coroa / Vou cantando esse rap na proteção de Jesus / Vamos partir pra Tijuca pra invadir o Morro do Cruz / Ih, Morro do Cruz! Qualquer dia tamo aí.. / Demorô, vamo lá! / Ih, Morro da Casa Branca! Qualquer dia tamo ai (Letra 3).

\footnotetext{
${ }^{11}$ Favela localizada no bairro Santa Cruz, Zona Oeste do Rio de Janeiro, sob domínio do CV na ocasião da produção desse funk.

12 Tipo de arma usada pela Polícia Militar e o Exército Brasileiro.

${ }^{13}$ Neste artigo, usamos para ilustrar a análise cinco trechos de letras de funk proibido de facção. As letras não revelam o título ou autor da música.

${ }^{14}$ Favela carioca da Zona Norte do Rio de Janeiro, sob domínio do CV na ocasião da produção do funk.

${ }^{15}$ Favela localizada no bairro de Vila Isabel, Zona Norte do RJ, sob domínio de uma facção rival do CV.
} 
Comando faz e não diz/Qual bandido que não representa $o$ Comando Vermelho feliz? / Qual bandido que não representa o morro da Mangueira feliz? (Letra 4).

O clima de disputa territorial entre as facções explica, em parte, a presença maciça dessa dimensão nas letras. Territórios precisam ser conquistados diariamente como forma de garantir a expansão e o fortalecimento da facção, os lucros com o tráfico e, mais do que isso, territórios não podem ser perdidos. Portanto a instabilidade é a marca do controle territorial. Os territórios de uma facção precisam ser lembrados e exibidos como troféus, explícita manifestação de um poder.

Nesse momento, o comércio varejista da droga se vê um tanto prejudicado com a ocupação das UPPs, e já surgem funks proibidôes sobre o tema. A experiência do território cantada nas letras, por outro lado, mostra forte carga afetiva, veiculando a felicidade ao domínio e pertencimento à facção. Poderíamos pensar que a vivência da conquista do território pelos grupos ligados ao tráfico de drogas (sua ocupação, a união de forças para obtê-la) é o cimento que o liga à sua identidade e reforça o valor simbólico da facção.

Se pensarmos o quanto os espaços populares são relegados à invisibilidade ou representados somente pelos seus aspectos negativos, fica mais fácil compreender o porquê da alegria e motivação na exaltação aos territórios presente nos proibidões, conforme, nessas menções, assumem quase sempre um lugar de evidência e de força. Isso sem contar o prazer do público, pertencente ou não ao tráfico, quando ouve a sua comunidade ser cantada em tramas, que, geralmente, transbordam virilidade e potência. Portanto, nas letras de funk proibido, a dimensão do território está ligada à força e ao poder das facções. São cantadas em bailes de comunidade por quem é e não é do tráfico.

Nas letras, a territorialização imposta pelo tráfico às diversas comunidades não é tratada ou sentida como problema. Por outro lado, na experiência real de moradores das favelas onde existe o tráfico, a territorialização e o cerceamento do direito de ir e vir nos territórios são considerados algo que se impõe de maneira brutal. Os moradores estão à mercê de fronteiras instáveis do tráfico e entendem que devem seguir a lógica da facção dominante, num jogo ambivalente entre a necessidade de reconhecerem o poder da facção, o temor da represália a quem contrariálo ou ignorá-lo e o poder do qual se revestem como numa expressão do princípio de participação de que falava Lévy-Bruhl (1922). 


\section{Questões finais}

A proposta deste artigo, utilizando como pano de fundo as letras de funk de facção, lança algumas questôes sobre como a territorialidade imposta pelo tráfico de drogas expressa a dinâmica desses grupos e ainda quais os desdobramentos dessa territorialização nas representações e práticas dos moradores. Como abordado ao longo do texto, a divisão dos territórios pelas facções acarretou mudanças nas relações estabelecidas pelos moradores com seus territórios de origem. As letras também retratam aspectos de um cotidiano que penetra a vivência dos moradores das favelas cariocas, em particular os jovens pobres, que, submetidos às forças do tráfico, reagem de diversas maneiras. Uns, seduzidos pelo poder desses grupos, enveredam pelo caminho do crime; outros, temendo provocar embates, criam dispositivos de convivência em que algumas regras passam a ser seguidas sem restrições; e há ainda os que cantam e dançam os proibidões com prazer e se sentem então revestidos daquele poder. Seja como for, a territorialização provocada pelo negócio das drogas é móvel e dinâmica, seguindo o movimento das invasões e troca de comando. No momento, assistimos a mais uma virada, desta vez com ocupação militar para o afastamento do tráfico armado. Os significados que mais essa mudança provocará, do ponto de vista simbólico, começam apenas a despontar e serão mais bem observados com o tempo.

Outros elementos, além dos explicitados acima, são transmitidos também por essas músicas, que expressam afetos variados e contribuem para a construção da representação social do universo das favelas, da sua juventude, na encruzilhada entre uma convivência próxima com o tráfico e as estratégias criadas para se lidar com ela. Parte de uma produção de subjetividade, as letras desse ritmo musical acabam por revelar uma realidade pluriterritorial complexa. A vivência de múltiplos territórios na vida contemporânea, sendo o contexto do tráfico mais uma via dessa produção, coloca os sujeitos do seu entorno numa relação às vezes confusa de identidade com os territórios. Para quem não vive a mesma realidade, a impressão que se tem é de uma identidade formada e um sentimento de pertencimento aos valores e à lógica da facção. Para quem vive o dia a dia dessa proximidade, não parece haver outra saída do que seguir as normas e adotar os códigos, sem que isso represente uma adesão automática e plena ao tráfico. Cantam-se os cantos da facção quando ela objetiva a importância e a força do território de origem dos moradores. À exceção de uns poucos sambas que louvaram determinadas comunidades (Mangueira, Salgueiro, por exemplo), quem já ouviu cantar loas a Vigário, ao Borel, à Chatuba, entre outros? De que outra forma esses espaços experimentam a sensação de impor respeito, ainda que pela violência? 
Com base na teoria das representações sociais, os fenômenos que surgem no cotidiano exigem compreensão e resposta imediata. Porém o ritmo acelerado da vida contemporânea nos submete à exposição de uma diversidade de mundos e práticas, que fazem da novidade uma marca comum em nossa sociedade (Jovchelovitch, 2008). Os moradores de favelas sob o domínio do tráfico, por vezes, são obrigados a vivenciar territorialidades ou identidades que não são as suas. As fronteiras do tráfico são objetivações do espaço dominado pela facção.

Neste artigo, deparamos a utilização dos territórios pelo tráfico de drogas e o que isso gera em termos de interditos que causam mudanças nas representações e práticas de seus integrantes e de moradores. A existência dos funks proibidos de facção reflete a segmentação do espaço urbano diante da disputa territorial entre facções criminosas. Os funks proibidos de facção, misturados a muitas outras questóes da vida bandida, trazem elementos que nos levam a entender o lugar dos territórios nessa disputa e, mais do que isso, o quanto essas fronteiras (in)visíveis necessitam ser respeitadas por trabalhadores e não trabalhadores do tráfico que aí se encontram. As sanções e violências contra aqueles que não as respeitam chegam, na maior parte das vezes, à morte.

Ao som grave e frenético das batidas do proibidão, ouvem-se nos bailes listas de lugares que se encontram nas alianças estabelecidas e sob o domínio da facção. O território parece ganhar status de personagem da vida cotidiana. Ele é regulamentado e regulamenta essa vida. Simbólica e fisicamente, está nas pessoas como as pessoas estão nele. Por isso o apego aos lugares de origem e a convergência com os cantos de exaltação "à favela onde eu nasci”, predominantemente, criados a partir das facçôes para balizar os espaços do comércio da droga. Os bailes funk e os proibidões formam parte desse cenário, espaço de socialização por excelência, eles terminam sendo um reduto da expressão de jovens na favela, suas práticas, a produção do prazer e da fruição da música, da dança, do namoro, dos cantos de guerra.

A facção, com suas práticas de comércio e de lazer (bailes, proibidóes), trouxe uma nova imagem para o território: ele é perigoso, mas é cobiçado, temido e valorizado. Essa é a dupla atração dos proibidões e das práticas ilegais da facção: ambos reforçam a ideia de valorização do lugar, de pertencimento, de grupo, sob o discurso da virilidade, do poder, da onipotência, marca tão característica da juventude adolescente. Por outro lado, na vivência real de moradores a territorialidade do tráfico é sentida de forma diferente, nem sempre com orgulho, mas também com desconforto pela restrição do direito de ir e vir e de usufruir dos territórios na cidade. 
A análise das letras de funk proibido revela que a territorialidade do tráfico se expressa por meio da dominação e controle, interferindo no cotidiano dos moradores, restringindo sua mobilidade e liberdade. Contudo, mesmo diante desse cenário, os moradores buscam estabelecer uma dinâmica própria, relevando a busca pelo equilíbrio entre a convivência inevitável com o crime e a construção de sentidos e práticas que se opõem aos limites e obstáculos impostos pelo tráfico.

\section{Referências}

Andrade, M. A. (1998). A identidade como representação e a representação da identidade. In: A. S. P. Moreira \& D. C. Oliveira (orgs.). Estudos interdisciplinares de representação social. (pp. 141-149). Goiânia: AB Editora.

Arruda et al. (2010). De pivete a funkeiro: genealogia de uma alteridade. Cadernos de Pesquisa, V.40, (140), PP. 407-425.

Bardin, L. (2003). L'analyse de contenu et de la forme des communications. In: Moscovici, S. \& Buschini, F. (pp. 243-270). Les méthodes des sciences humaines. Paris: PUF.

Fernandes, F. L. (2009). Violência, medo e estigma: efeitos socioespaciais da atualização do mito da marginalidade no Rio de Janeiro. Tese de Doutorado, Programa de Pós-Graduação em Geografia, Universidade Federal do Rio de Janeiro, Rio de Janeiro.

Giménez, G. (2007). La Frontera Norte como representación y referente cultural en México. Territorio y frontera. Cultura y Representaciones Sociales, $2(3), 17-34$.

Giménez, G. (2000). Territorio, cultura e identidades. La región sociocultural. In: Rosales, R. (org.). (pp. 19-52). Globalización y regiones en México. México: UNAM-Fcps-PUEC.

Guedes, M. (2007). A música que toca é nós que manda: um estudo sobre o proibidão. Dissertação de Mestrado, Programa de Pós-graduação em Psicologia, PUC, Rio de Janeiro.

Haesbaert, R. (2002). Territórios alternativos. São Paulo: Contexto. 
Herschmann, M. (2005). O funk e o hip-hop invadem a cena. Rio de Janeiro: Editora UFRJ.

Jodelet, D. (2005). Experiência e representaçōes sociais. In: Menin, M. S. de S. \& Shimizu, A. de Moraes (orgs.). (pp. 23-56). Experiência e representação social: questôes teóricas e metodológicas. São Paulo: Casa do Psicólogo.

Jodelet, D. (1984). Representation sociale: phénomènes, concept et theorie. In: Moscovici, S. (org). (pp. 12-32). Psychologie Sociale. Paris: Presses Universitaires de France.

Jovchelovitch, S. (2008). Os contextos do saber: representações, comunidade e cultura. Petrópolis: Vozes.

Leite, M. P. \& Oliveira, P. P. (2005). Violência e insegurança nas favelas cariocas: o ponto de vista dos moradores. Revista Praia Vermelha. Estudos de política e teoria social. [Cidade de Segregação], 13, 14-43.

Lévy-Bruhl, L. (1922). La mentalité primitive. Paris: Alcan.

Medeiros, J. (2006). Funk carioca: crime ou cultura? O som dá medo. E prazer. São Paulo: Terceiro Nome.

Moscovici, S. (1978). A representação social da psicanálise. Rio de Janeiro: Jorge Zahar.

Raffestin, C. (1993). Por uma Geografia do poder. São Paulo: Ática.

Silva. J. S. et al. (2008). Grupos criminosos armados com domínio de território: reflexões sobre a territorialidade do crime na Região Metropolitana do Rio de Janeiro. In: Justiça Global (org.). (pp. 16-24). Segurança, tráfico e milícias no Rio de Janeiro. Rio de Janeiro: Fundação Heinrich Boll.

Valladares, L. (2000). A gênese da favela carioca: a produção anterior às ciências sociais. Revista Brasileira de Ciências Sociais, 15 (44), 5-34.

Vianna, H. (1988). O mundo funk carioca. Rio de Janeiro: Jorge Zahar. Zaluar, A. (1994). Condomínio do Diabo. Rio de Janeiro: Revan. 